\title{
Moss-Derived Mesoporous Carbon as Bi-Functional Electrode Materials for Lithium-Sulfur Batteries and Supercapacitors
}

\author{
Wen Lei ${ }^{1, * \mathbb{D}}$, Haipeng Liu ${ }^{1}$, Junlei Xiao ${ }^{1}$, Yang Wang ${ }^{2}$ and Liangxu Lin ${ }^{1,3, * \mathbb{D}}$ \\ 1 The State Key Laboratory of Refractories and Metallurgy, and Institute of Advanced Materials and \\ Nanotechnology, Wuhan University of Science and Technology, Wuhan 430081, China; \\ lhpWUST@gmail.com (H.L.); pvt516987834@gmail.com (J.X.) \\ 2 Hefei Guoxuan High-Tech Power Energy Co., Ltd., 599 Daihe Road, Hefei 230000, China; \\ 1152036@dhu.edu.cn \\ 3 ARC Centre of Excellence for Electromaterials Science, Intelligent Polymer Research Institute, Institute of \\ Innovative Materials (AIIM), Innovation Campus, University of Wollongong, Wollongong 2500, Australia \\ * Correspondence: leiwen@wust.edu.cn (W.L.); L.Lin@wust.edu.cn (L.L.);
} Tel.: +86-02768862825 (W.L.); +61-242215441 (L.L.)

Received: 16 December 2018; Accepted: 6 January 2019; Published: 10 January 2019

\begin{abstract}
In this work, we reported a moss-derived biomass porous carbon (MPC) as a bi-functional electrode material for both the lithium-sulfur battery and the supercapacitor. The MPC was prepared from a high-temperature calcination procedure using the moss as the carbonaceous precursor. Using $\mathrm{NaOH}$, the MPC was activated to give a mesoporous structure with a high specific surface area $\left(1057.1 \mathrm{~m}^{2} \mathrm{~g}^{-1}\right)$ and large pore volume $\left(0.72 \mathrm{~cm}^{3} \mathrm{~g}^{-1}\right)$. When it was used as the cathode material in lithium-sulfur batteries, the MPC material realized a sulfur loading and exhibited a remarkably improved electrochemical performance, i.e., a high discharge capacity of $1070 \mathrm{mAh} \mathrm{g}^{-1}$ at $0.1 \mathrm{C}$. This activated MPC also worked well as a capacitive electrode in supercapacitors, demonstrating a high specific capacitance of $332 \mathrm{~F} \mathrm{~g}^{-1}$ (scan rate of $1.0 \mathrm{~A} \mathrm{~g}^{-1}$ ) and a high capacity retention $>97 \%$ in a long-term cycle of 1000 charge/discharges. This work demonstrated a facile method for the utilization of activated waste biomass material for future clean energy applications.
\end{abstract}

Keywords: moss; biomass derived carbon; lithium-sulfur batteries; supercapacitors

\section{Introduction}

To satisfy the increasing demand for cheap and efficient clean energy technologies, the development of low cost rechargeable energy storage devices with high specific energy and high stability is highly sought after [1,2]. Among various secondary batteries developed so far, the lithium-sulfur (Li-S) batteries assembled by lithium metal anodes and sulfur cathodes are highly competitive and are promising energy storage devices [3]. Theoretically, they have very high specific capacity $\left(1675 \mathrm{mAh} \mathrm{g}^{-1}\right)$ and specific energy $\left(2600 \mathrm{Wh} \mathrm{Kg}^{-1}\right)$, and an average operating voltage of $2.1 \mathrm{~V}$, which is superior to the current commercial lithium-ion batteries [4]. The manufacture of such Li-S batteries is also affordable because of the low-cost and the abundant resource of the raw material [5].

Despite these advantages, the practical application of Li-S batteries is still limited by several technical weaknesses, such as the high solubility of the lithium polysulfide and the formation of unfavorable intermediate products in electrolytes during the discharge processes. The latter reduces the utilization of raw materials, increasing the cost and causing irreversible loss of capacity [5-8]. To overcome these challenges, several strategies have been explored, including the use of novel 
cathode materials [9-13], the surface protection of the lithium anode [14-17], the modification of the electrolyte [18-20], and the optimization of the cell configuration [21-23]. In these approaches, the development of a suitable conductive porous carbon material is highly promising and can be considered as one of the most direct ways to improve the performance of the Li-S battery [24]. For such purposes, commercial carbon black [25], carbon nanotubes, and other carbon-based materials [26] have been extensively tested as cathode materials for Li-S batteries. However, for most of these carbon materials, their fabrication processes should be further simplified to reduce the cost of scale-up production.

Unlike the above traditional materials, the emerging biomass derived carbon materials might be an ideal carbon electrode for high-performing Li-S batteries, owing to their low production costs, renewable/environmentally friendly resources, and adjustable physical/chemical properties $[27,28]$. The activated bio-mass materials could be readily used in Li-S batteries [29,30]. For example, Chung et al. employed a natural material obtained from domestic waste as the cathode carrier to achieve a high discharge capacity of $1327 \mathrm{mAh} \mathrm{g}^{-1}$ (scan rate of $0.05 \mathrm{mV} \mathrm{s}^{-1}$ ) and a good stability $(97 \%$ Columbic efficiency retention after 100 cycles) [31]. Ji et al. prepared mesoporous sulfur/carbon composites using a melting process [9]. The large pore volume and the uniform mesoporous carbon structure allowed the successful encapsulation of sulfur into the pore space, yielding a high capacity of $830 \mathrm{mAh} \mathrm{g}^{-1}$ (at $0.1 \mathrm{C}$ ), with acceptable stability (71\% capacity remained after 100 cycles). These achievements encouraged us to develop the alternative biomass-derived carbon material, the moss, as the electrode material for the Li-S battery. As we know, moss is an aquatic plant and a worldwide water contaminant. Utilization of the cheap and abundant moss in valuable Li-S batteries and similar energy storage approaches has positive significance in promoting clean energy technologies. In the long-term perspective of environmental conservation and sustainable development, searching for valuable biomass derived carbon materials and exploring their applications in other fields, such as supercapacitors, has also been regarded as an alternative choice. The natural superiorities of biomass derived carbon materials, e.g., well-developed porous structure [32], large specific surface area [33], and different types of heteroatoms doping [34], endow them with unparalleled advantages when used as electrode materials for high performance supercapacitors [35].

In this paper, we demonstrated a high-performing (e.g., high discharge specific capacity, good cycling stability and rate performance) Li-S battery using the cathode material from the moss-derived porous carbon (MPC) biomass. This MPC with a high surface area was activated with a conventional approach (heating reaction of the carbon contained materials with $\mathrm{NaOH}$ ), which is also capable of providing a high specific capacitance when used in supercapacitors. Given the natural porous structure and abundant resources, this work demonstrated that moss-derived porous carbons can be a promising electrode material for energy storage and conversions.

\section{Experimental}

\subsection{Preparation of MPC and Activation Process}

The MPC was obtained through the simple cleaning and high-temperature calcination of moss (Jin River, Tianjin, China). First, moss was ultrasonicated in deionized water and alcohol. It was then placed in a dry box and kept at $60^{\circ} \mathrm{C}$ for $12 \mathrm{~h}$. The dried moss was calcined at $800{ }^{\circ} \mathrm{C}$ (heating rate: $5{ }^{\circ} \mathrm{C} \mathrm{min}{ }^{-1}$ ) for $3 \mathrm{~h}$ in Ar atmosphere, and then naturally cooled down. The as-obtained product was referred to as MPC. Next, $\mathrm{NaOH}$ was employed as the activator to increase the specific surface area and pore volume of the MPC. Briefly, MPC was dispersed into $1.0 \mathrm{M} \mathrm{NaOH}$ solution $(\mathrm{NaOH} / \mathrm{MPC}$ mass ratio of 3:1) and stirred for $12 \mathrm{~h}$. The mixture was filtered and then calcined at $800{ }^{\circ} \mathrm{C}$ in Ar for another $2 \mathrm{~h}$. After that, the product was rinsed with $1.0 \mathrm{M}$ hydrochloric acid $(\mathrm{HCl})$ and deionized water until the $\mathrm{pH}$ was 7 . 


\subsection{Characterization}

Morphologies of the MPC sample were characterized using scanning electron microscopy (SEM) and transmission electron microscopy (TEM). The structure of the MPC sample was investigated using Raman spectroscopy and X-ray diffraction (XRD). Raman spectra were performed on a LabRam HR800 spectrometer (HORIBA, Kyoto, Japan) with a $532 \mathrm{~nm}$ laser excitation. XRD was employed to confirm the graphite crystal structure using $\mathrm{Cu}$ Ka radiations $(\lambda=0.15406 \mathrm{~nm})$ at a speed of $2^{\circ} \mathrm{min}^{-1}$. The $X$-ray photoelectron spectroscopy (XPS) was performed on a Kratos AXIS Ultra DLD X-ray photoelectron spectroscopy (Kratos, Manchester, UK) (excitation source of Al Ka). The binding energy of XPS was calibrated based on C1s $(284.5 \mathrm{eV})$. The specific surface area and pore size distribution was analyzed from the $\mathrm{N}_{2}$ adsorption-desorption isotherms with ASAP 2020 (Micromeritics, Norcross, GA, USA). The sulfur content was determined using thermogravimetric analysis (TGA) under $\mathrm{N}_{2}$ atmosphere.

\subsection{Electrode Preparation and Electrochemical Measurements}

Preparation of the S@MPC: The as-prepared MPC sample was mixed with sulfur at the weight ratio of MPC/sulfur = 1:3. After sufficient grounding in a mortar, the mixture was placed into the reaction vessel protected with Ar, and then heat treated at $155^{\circ} \mathrm{C}$ for $12 \mathrm{~h}$ to give S@MPC. The cathode for the Li-S battery test was fabricated through a conventional slurry-coating process. Briefly, the S@MPC, the polyvinylidene fluoride (PVDF) binder, and the acetylene black were mixed and ground at the mass ratio of 8:1:1. After adding appropriate amounts of N-Methyl-2-pyrrolidone (NMP), the slurry was uniformly spread onto an aluminum foil and dried. The resulting pole piece was then fashioned into a round piece with diameter of $1.2 \mathrm{~cm}$ and used as sulfur electrodes. The anode was made of the lithium metal. The electrolyte was $1.0 \mathrm{M}$ lithium bis (trifluoromethanesulfonyl) imide (LiTFSI) in 1,3-dioxolane (DOL) and 1,2-dimethoxyethane (DME) (1:1 by volume). The 2025-type coin cell was assembled inside an Ar-filled glove box, and the Galvanostatic charge/discharge measurement was performed on a multichannel battery tester (BTS-5V5mA, Neware, Shenzhen, China). All the electrochemical tests were performed at room temperature. Electrodes for the supercapacitor test were prepared by mixing MPC powders with the super $\mathrm{P}$ and the polytetrafluoroethylene (PTFE) emulsion at a weight ratio of 8:1:1. Then, $6.0 \mathrm{M} \mathrm{KOH}$ solution was used as the electrolyte in a three-electrode test system. The mass load of each electrode was approximately $3.0 \mathrm{mg}$.

\section{Results and Discussion}

The XRD pattern of the as-prepared MPC is shown in Figure 1a, giving two broad diffraction peaks at around 26.2 and $42.8^{\circ}$. These two peaks can be ascribed to the (002) and (100) diffractions of the graphite structure (ICDD cards: 41-1487). The weak and broad diffraction peaks meant the long-range disorder of the graphite structure due to the random packing of the sheets (would be further clarified). Nevertheless, our Raman analyses suggested that the local domain of the MPC was highly graphitized with a continuous $\mathrm{sp}^{2}$ benzene-ring structure. As suggested in Figure $1 \mathrm{~b}$, the $\mathrm{D}$ and G bands of the MPC were identified at around 1321 and $1597 \mathrm{~cm}^{-1}$, corresponding to the breathing mode of defect (disordered) carbon atoms and the vibration of lattice carbon atoms, respectively. The $\mathrm{I}_{\mathrm{D}} / \mathrm{I}_{\mathrm{G}}$ (relative intensity ratio of the $\mathrm{D}$ and $\mathrm{G}$ bands) could reflect the extent of graphitization and alignment of the graphene planes in the carbon-based materials [13]. The $\mathrm{I}_{\mathrm{D}} / \mathrm{I}_{\mathrm{G}}$ value in Figure $1 \mathrm{~b}$ is larger than 1 considering the contribution of the $G$ peak by a D2 peak at around $1620 \mathrm{~cm}^{-1}$, indicating a high 1 structure disorder of the MPC material. Compared with highly reduced graphene and graphite materials (e.g., $1587 \mathrm{~cm}^{-1}$ ) [35], the G band of our sample was slightly blue shifted probably owing to the chemical doping, i.e., the out-of-plane doping, which increased the dangling strength of the $\mathrm{C}-\mathrm{C} / \mathrm{C}=\mathrm{C}$ (will be discussed later). 

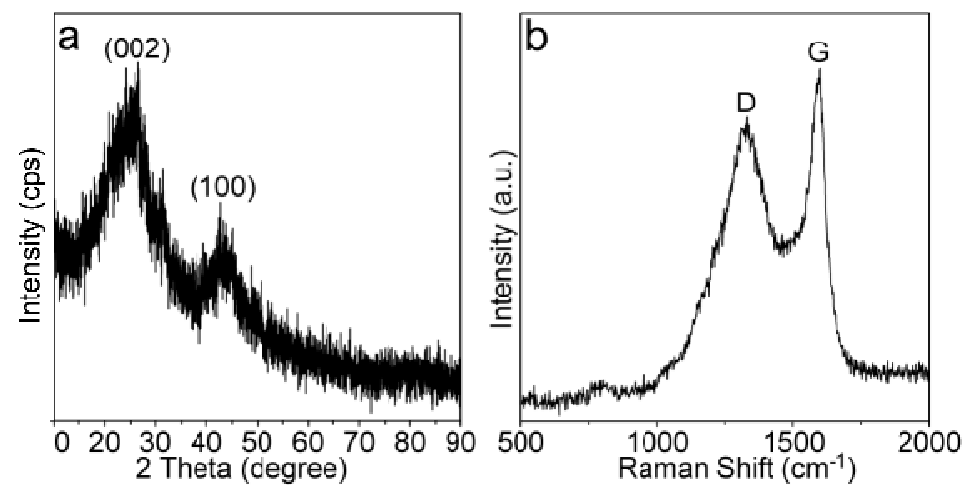

Figure 1. (a) X-ray diffraction (XRD) pattern and (b) Raman spectrum of the as-prepared moss-derived biomass porous carbon (MPC).

Figure 2a-c show the SEM and TEM images of the MPC. According to Figure 2a, the MPC has the evident porous surface structure, which is further confirmed by the TEM observation (Figure $2 b$ ). Our TEM observations also confirmed the (002) lattice of around $0.34 \mathrm{~nm}$ from many graphite domains with some dislocated interlayers (Figure 2c). Such a porous structure explains well the broad and weak XRD diffraction peaks (Figure 1a) and the strong D mode of the MPC (Figure 1b). Existence of this porous structure, in principle, can improve the electrochemical performance of the lithium-sulfur battery by increasing the specific surface area and pore volume of the electrode material. Unlike the MPC material, pores of the S@MPC were not clear (Figure 2d), suggesting that our preparation had efficiently filled the sulfur particles into the pore space of the MPC material. To further verify the distribution of sulfur, oxide, and carbon in the S@MPC sample, we carried out the energy dispersive spectroscopic (EDS) elemental mapping analysis (Figure 2e), confirming the homogenous dispersion of these elements in the S@MPC sample. The $\mathrm{O}$ and $\mathrm{N}$ were derivated from the raw material of moss and incorporated into the $\mathrm{sp}^{2} \mathrm{C}-\mathrm{C} / \mathrm{C}=\mathrm{C}$ structure.
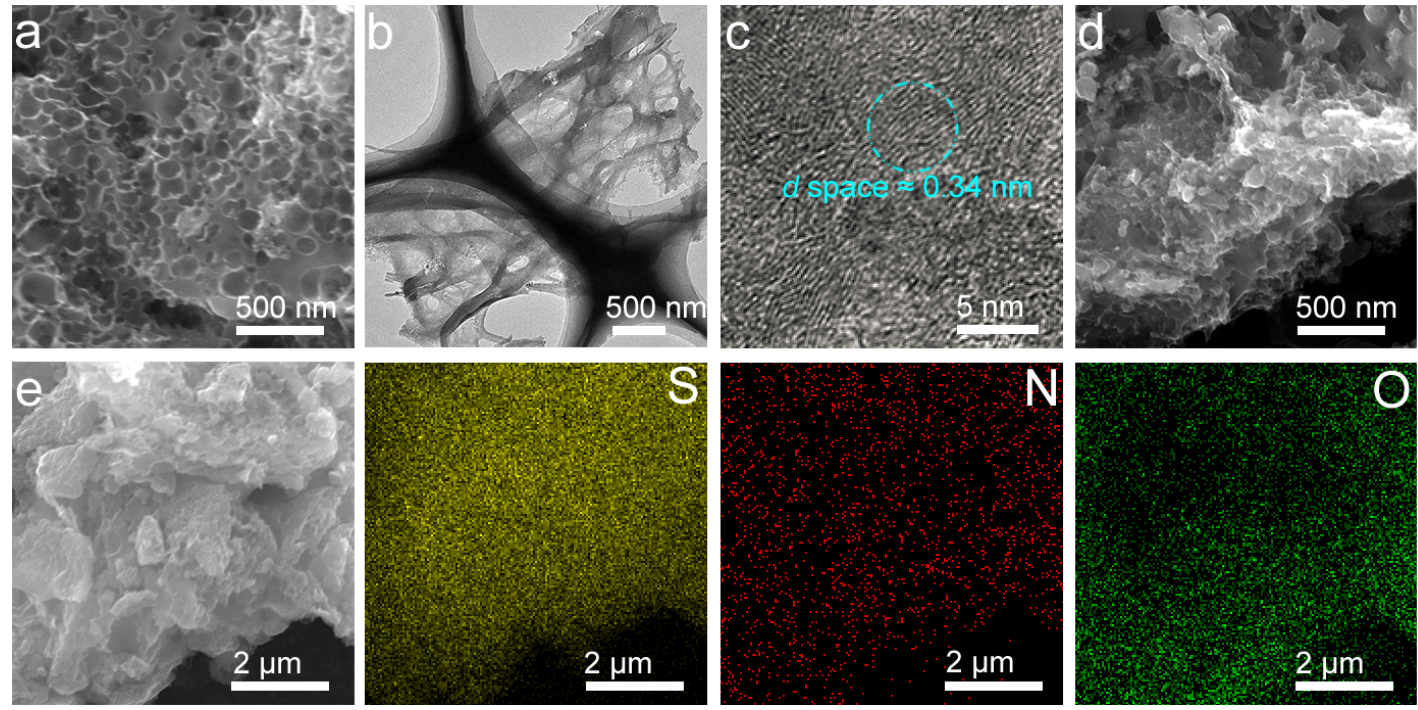

Figure 2. (a-c) Scanning electron microscopy SEM (a) and bright field transmission electron microscopy (TEM) images (b,c) of the MPC; (d) SEM image of the S@MPC; (e) the SEM and corresponding S, N, and $\mathrm{C}$ mappings of the S@MPC.

Figure 3a shows the XPS full survey of the MPC, giving the atomic ratios of $\mathrm{O}$ and $\mathrm{N}$ at around $11.02 \%$ and $9.82 \%$, respectively. C1s XPS spectrum of the MPC (Figure $3 \mathrm{~b}$ ) was composed of four binding energy peaks corresponding to the $\mathrm{C}-\mathrm{C} / \mathrm{C}=\mathrm{C}(284.7 \mathrm{eV}), \mathrm{C}-\mathrm{N}(285.3 \mathrm{eV}), \mathrm{C}-\mathrm{O}$ or $\mathrm{C}=\mathrm{O}$ $(286.4 \mathrm{eV})$, and $\mathrm{O}-\mathrm{C}=\mathrm{O}(288.9 \mathrm{eV})$, respectively [31]. The existence of the $\mathrm{O}$-containing groups was 
also confirmed by the O1s XPS spectrum (Figure 3c). C=O and the N-C structure in the MPC was complex, but could be recognized as the pyridinic, pyrrolic, and quaternary $\mathrm{N}$ with binding energies at around 399.1, 399.8, and $400.6 \mathrm{eV}$, respectively (Figure 3d) [30].
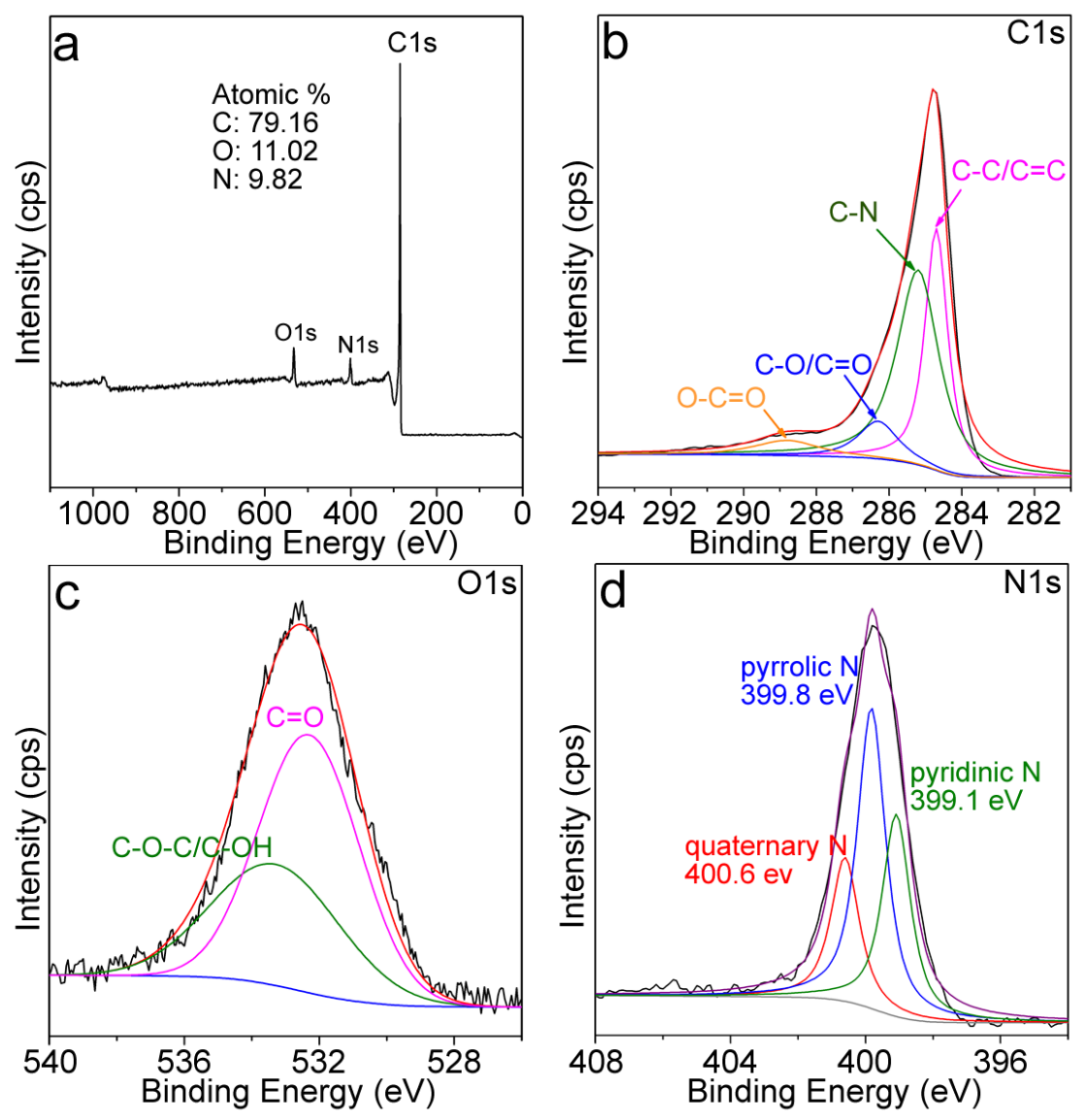

Figure 3. (a) X-ray photoelectron spectroscopy (XPS) Full survey; (b) C1s, (c) O1s, (d) N1s of the MPC.

Figure $4 \mathrm{a}, \mathrm{b}$ show the $\mathrm{N}_{2}$ adsorption-desorption isotherms and the pore size distributions of both the MPC and S@MPC. The adsorption-desorption isotherm of the activated MPC was a type IV isotherm, suggesting the existence of abundant mesopores (a pore volume of $0.72 \mathrm{~cm}^{3} \mathrm{~g}^{-1}$ ). The surface area calculated from the adsorption curve with the BET (Brunauer-Emmett-Teller) method was $1057.1 \mathrm{~m}^{2} \mathrm{~g}^{-1}$. The pore size distribution of the MPC derived from the desorption curve with the BJH (Barrett-Joyner-Halenda) method gave a pore size of around 3.5-4.0 nm. In contrast, the BET surface area of the S@MPC material was really low $\left(10.5 \mathrm{~m}^{2} \mathrm{~g}^{-1}\right)$, corresponding to the disappearance of the mesopore (Figure $4 \mathrm{~b}$ ). This phenomenon was reasonable, since both the large pores (see SEM images, Figure 2) and the mesopores were filled by the sulfur during the preparation.

The exact sulfur loading in the porous MPC sample was determined by the TGA technique (Figure 4c). At $200-320^{\circ} \mathrm{C}$, the TGA curves of both the sulfur and S@MPC showed obvious weight loss, corresponding to large decomposition of sulfur. According to this weight loss stage, the sulfur content in the S@MPC was determined to be $58 \mathrm{wt} \%$. Figure $4 \mathrm{~d}$ shows the XRD patterns of the sulfur and S@MPC. The XRD pattern of the MPC is also shown in this figure for better comparison. Diffractions from the crystallized sulfur (see the diffraction peaks from the sulfur raw material) were commonly found in the S@MPC, which were narrow and intense. In the XRD pattern of the MPC, diffraction peaks from initial MPC was nearly invisible owing to the strong diffractions from the crystallized sulfur. 

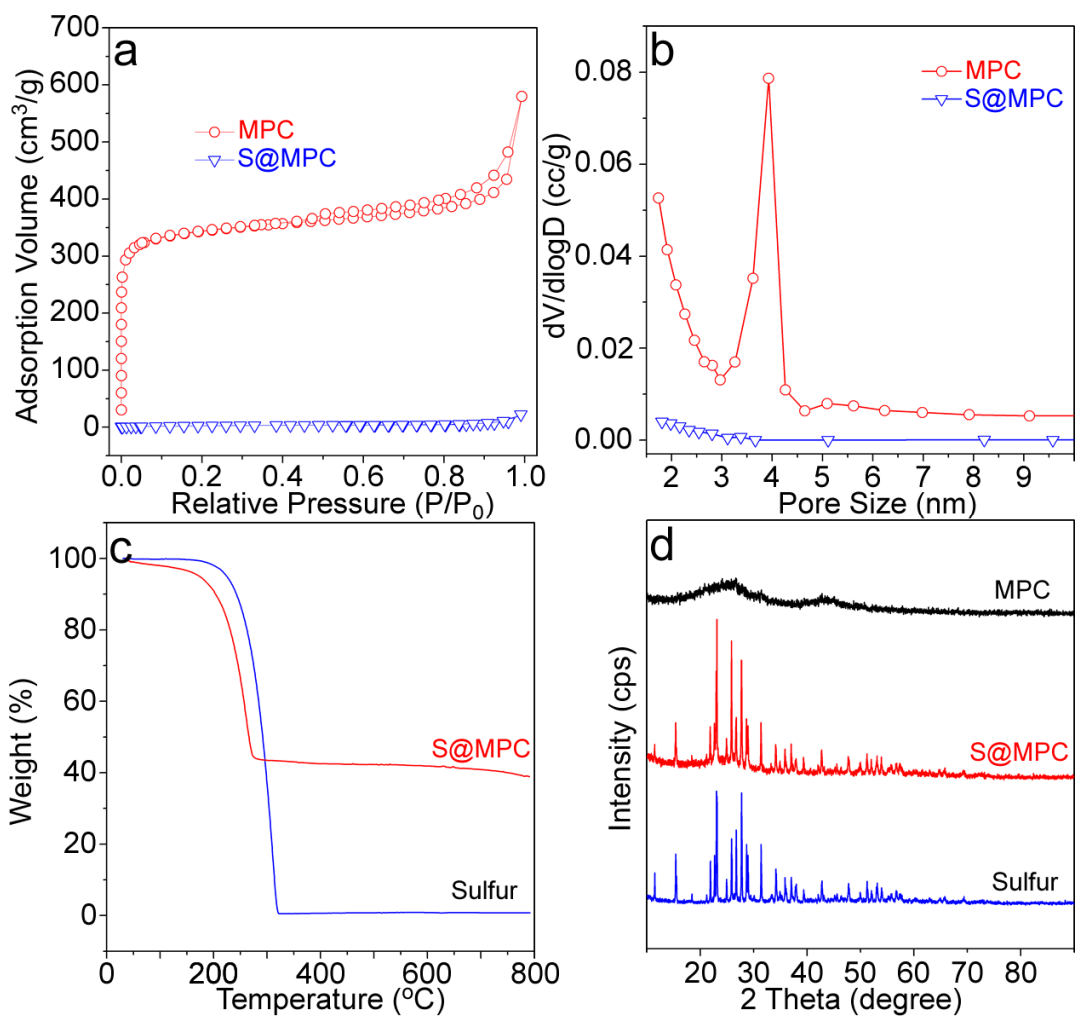

Figure 4. (a) $\mathrm{N}_{2}$ adsorption-desorption isotherms; (b) BJH pore size distribution; (c) TGA curves of the sulfur and S@MPC materials; (d) XRD patterns of the MPC, sulfur, and S@MPC materials. Note: XRD backgrounds of these samples were shifted for better comparison.

The above characterizations suggested that: (1) Moss raw materials were successfully converted to the carbon material (with $\mathrm{N}$ and $\mathrm{O}$ dopants) and activated with high surface area, and (2) Sulfur particles were successfully filled into the pores of the MPC with a high loading content $(58 \mathrm{wt} \%)$. Building on these preparations, we fabricated the Li-S battery and measured the corresponding electrochemical performances. Figure 5a shows the charge/discharge curves of the Li-S battery with the cathode material of S@MPC. The discharge processes had two plateaus near 2.28 and $2.09 \mathrm{~V}$, corresponding to the reduction of sulfur and the transformation of long-chain lithium polysulfide to the short-chain lithium sulfide, respectively. The charging plateaus appeared at around $2.33 \mathrm{~V}$, representing the transition from low-order lithium sulfide to higher-order polysulfide and sulfur. The initial discharge specific capacity of the S@MPC electrode was measured to be $1070 \mathrm{mAh} \mathrm{g}^{-1}$. After a functional cycle of 100, the discharge specific capacity of the S@MPC could still remain at $\sim 708 \mathrm{mAh} \mathrm{g}^{-1}$, indicating its good cyclic stability (Figure 5b). As mentioned earlier, the discharge specific capacity of the S@MPC could be attributed to the high surface area and porosity in the MPC through $\mathrm{NaOH}$ treatment, implying that the dissolution of polysulfides into the electrolyte was largely alleviated by the porous structure of the MPC. Figure $5 \mathrm{c}$ shows the rate capability of the S@MPC electrode. At current densities of 0.1, 0.2, 0.5, 1, and 2 C, the discharge capacities of the S@MPC were found to be $832,717,596,521$, and $373 \mathrm{mAh}^{-1}$, respectively. The specific capacity of the S@MPC reached $763 \mathrm{mAh} \mathrm{g}^{-1}$ upon the current density return to $0.1 \mathrm{C}$. The Nyquist plots of the S@MPC electrode (Figure 5d) suggested a low charge transfer resistance, the Warburg impedance, and the ohmic resistance (including the electrolyte and electrode resistances). All these observations suggested that S@MPC with a large number of mesoporous structures could maintain reasonable specific capacity, while exhibiting great stability and rate performance. 

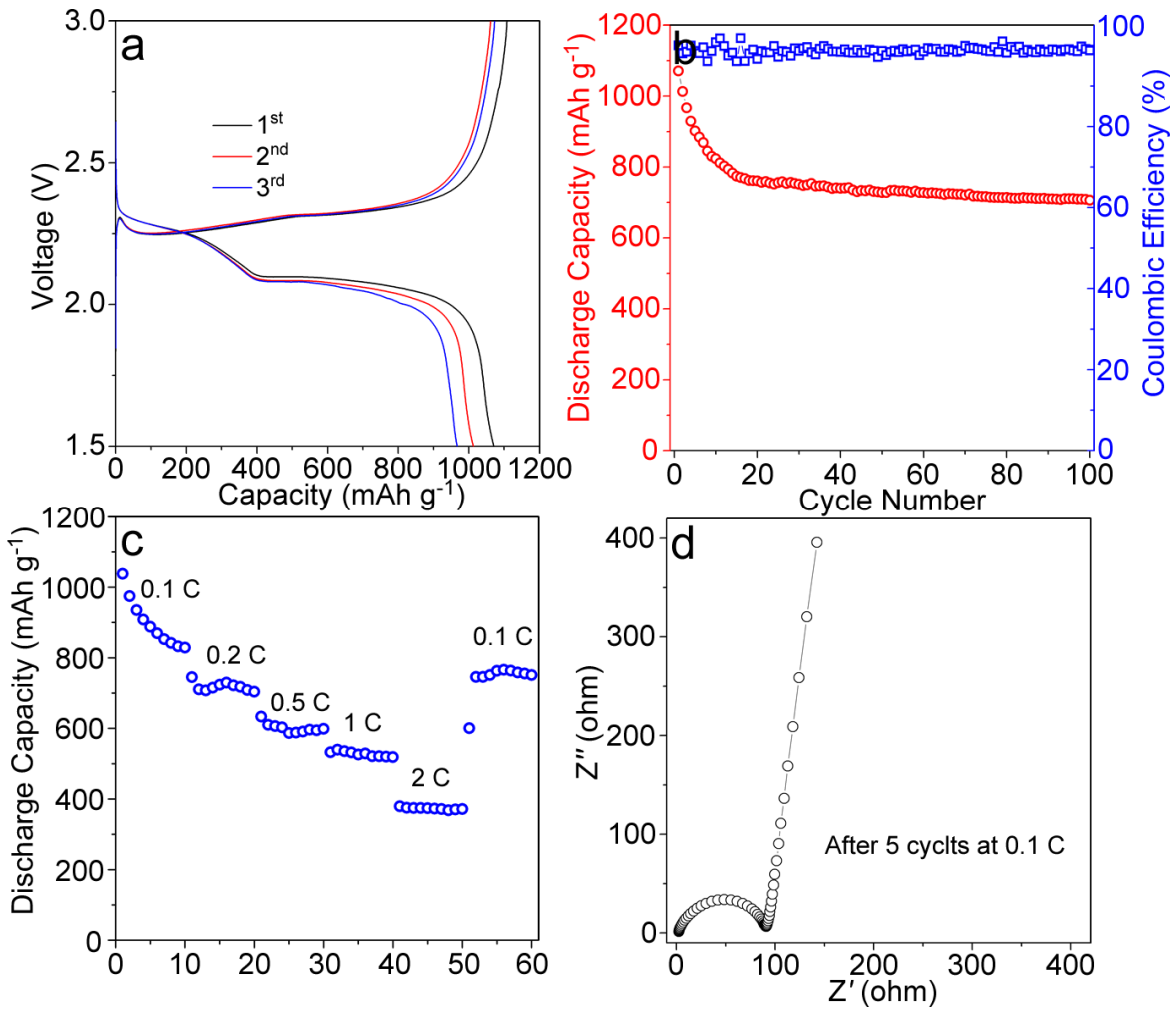

Figure 5. (a) Charge and discharge performance of the S@MPC electrode at $0.1 \mathrm{C}$; (b) Cycling performance and coulombic efficiency of the S@MPC electrode at 0.1 C; (c) Rate performance of the S@MPC electrode; (d) The Nyquist plots of S@MPC electrode.

Considering several features of the prepared MPC material, such as the porous structure with open pores, the high level of $\mathrm{N}$ doping, and the high specific surface area, we further evaluated its electrochemical performances as a supercapacitor. Fabrication of the supercapacitor electrode has been described in the experimental section. Figure 6a shows the CV (Cyclic Voltammetry) curves at different scan rates, which revealed the satisfactory capacitance behavior in a voltage range of -1.0 to $0 \mathrm{~V}$ (vs. $\mathrm{Hg} / \mathrm{HgO}$ ) in $6.0 \mathrm{M} \mathrm{KOH}$ electrolyte. The galvanostatic charge/discharge curve of the MPC electrode suggested a high specific capacitance of $332 \mathrm{~F} \mathrm{~g}^{-1}$ at the current density of $1.0 \mathrm{~A} \mathrm{~g}^{-1}$, which was much higher than many of other similar biomass derivated carbon electrodes (Figure 6b).
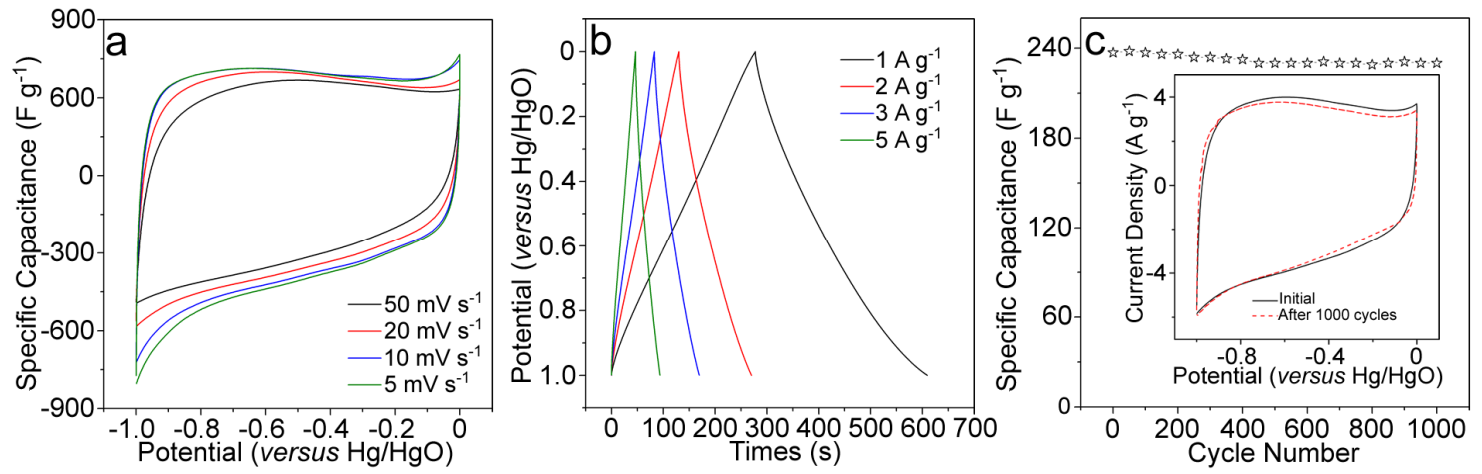

Figure 6. (a) CV curves of the as-prepared MPC electrode at different scan rates; (b) Charge/discharge curves of the as-prepared MPC electrode at different current density; (c) Cycle performance of the MPC electrode at current density of $5.0 \mathrm{~A} \mathrm{~g}^{-1}$.

For a better comparison, some recently published data of N-doped carbon materials from biomass/biowaste are listed in Table 1 . The capacitances are still high at higher current densities of 2 , 
3, and $5 \mathrm{~A} \mathrm{~g}^{-1}$, i.e., a capacitance of $237 \mathrm{~F} \mathrm{~g}^{-1}$ was achieved at $5 \mathrm{~A} \mathrm{~g}^{-1}$. We have further evaluated the cycling performance of the MPC based electrode at the current density $5 \mathrm{~A} \mathrm{~g}^{-1}$ (Figure 6c). During the performed 1000 cycles, the loss in specific capacitance based on the maximum value $\left(237 \mathrm{~F} \mathrm{~g}^{-1}\right)$ was less than 3\%, suggesting a significantly high stability of the capacitance and the electrode. The stable electrochemical performance of the electrode was further confirmed by the similar CV curves after before and after 1000 cycles (Figure 6c, inset).

Table 1. Comparison of electrochemical performance of the biomass-derived $\mathrm{N}$ doped carbon materials in a three-electrode system.

\begin{tabular}{ccccc}
\hline Biomass Materials & Activator & C/F g & MC & Ref \\
\hline Banana peel & Zinc complexes & 206 & $1.0 \mathrm{~A} \mathrm{~g}^{-1}$ & {$[36]$} \\
Shiitake mushrooms & $\mathrm{H}_{3} \mathrm{PO}_{4}+\mathrm{KOH}$ & 306 & $1.0 \mathrm{~A} \mathrm{~g}^{-1}$ & {$[37]$} \\
Bamboo & $\mathrm{KOH}$ & 301 & $0.1 \mathrm{~A} \mathrm{~g}^{-1}$ & {$[38]$} \\
Cotton & $\mathrm{KOH}$ & 283 & $1.0 \mathrm{~A} \mathrm{~g}^{-1}$ & {$[39]$} \\
Willow catkin & $\mathrm{KOH}$ & 298 & $0.5 \mathrm{~A} \mathrm{~g}^{-1}$ & {$[40]$} \\
Flour & $/$ & 261 & $1.0 \mathrm{~A} \mathrm{~g}^{-1}$ & {$[41]$} \\
Bamboo shoot & $\mathrm{Hydrothermal}$ & 270 & $5.0 \mathrm{~A} \mathrm{~g}^{-1}$ & {$[42]$} \\
Agaric & $\mathrm{KOH}$ & 324 & $1.0 \mathrm{~A} \mathrm{~g}^{-1}$ & {$[43]$} \\
Cigarette filter & $/$ & 154 & $1.0 \mathrm{~A} \mathrm{~g}^{-1}$ & {$[44]$} \\
Gelatin & $\mathrm{NaOH}$ & 281 & $5.0 \mathrm{~A} \mathrm{~g}^{-1}$ & {$[45]$} \\
Eggshell membrane & $\mathrm{Air}$ & 297 & $1.0 \mathrm{~A} \mathrm{~g}^{-1}$ & {$[46]$} \\
This work & $\mathrm{NaOH}$ & 332 & $1.0 \mathrm{~A} \mathrm{~g}^{-1}$ & $/$ \\
\hline
\end{tabular}

C: Specific capacitance. MC: Measurement condition.

\section{Conclusions}

Moss-derived porous carbon material was evaluated as a sulfur host cathode in lithium-sulfur batteries. After being activated with $\mathrm{NaOH}$, the MPC material possessed a mesoporous structure with an enhanced specific surface area and large pore volume. As a result, the S@MPC electrode gives a high discharge specific capacity, cycle stability, and rate performance. Moreover, this prepared MPC material also performed well as the electrode for the supercapacitor, giving a high capacitance and very high stability. The work here demonstrated a facile method for the utilization of moss waste biomass as alternative electrode materials for both lithium-sulfur batteries and supercapacitors.

Author Contributions: Conceptualization, W.L.; Data curation, H.L. and J.X.; Formal analysis, H.L.; Investigation, Y.W.; Project administration, Y.W.; Supervision, L.L.; Writing—original draft, W.L.; Writing—review \& editing, L.L.

Funding: This research received no external funding.

Acknowledgments: Support from the UOW VC Fellowship and University start-up fund (WUST) are gratefully acknowledged. The authors would like to thank the Australian National Fabrication Facility-Materials node for facility access.

Conflicts of Interest: The authors declare no conflict of interest.

\section{References}

1. Braff, W.A.; Mueller, J.M.; Francik, J.E. Value of storage technologies for wind and solar energy. Nat. Clim. Chang. 2016, 6, 964-969. [CrossRef]

2. Miller, J.R.; Simon, P. Electrochemical capacitors for energy management. Science 2018, 321, 651-652. [CrossRef] [PubMed]

3. Li, G.; Chen, Z.; Lu, J. Lithium-sulfur batteries for commercial applications. Chem 2018, 4, 3-7. [CrossRef]

4. Daniel, C.; Besenhard, J.O. Handbook of Battery Materials, 2nd ed.; Wiley: New York, NY, USA, 2012.

5. Manthiram, A.; Fu, Y.; Su, Y.-S. Challenges and prospect of lithium-sulfur batteries. Acc. Chem. Res. 2013, 46, 1125-1134. [CrossRef] [PubMed] 
6. Xu, G.; Ding, B.; Pan, J.; Nie, P.; Shen, L.; Zhang, X. High performance lithium-sulfur batteries: Advances and challenges. J. Mater. Chem. A 2014, 2, 12662-12676. [CrossRef]

7. Li, Q.; Zhang, Z.; Zhang, K.; Fang, J.; Lai, Y.; Li, J. A simple synthesis of hollow carbon nanofiber-sulfur composite via mixed-solvent process for lithium-sulfur batteries. J. Power Sources 2014, 256, 137-144. [CrossRef]

8. Chen, L.; Shaw, L.L. Recent advances in lithium-sulfur batteries. J. Power Sources 2014, 267, 770-783. [CrossRef]

9. Geng, Z.; Xiao, Q.; Wang, D.; Yi, G.; Xu, Z.; Li, B.; Zhang, C. Improved electrochemical performance of biomass-derived nanoporous carbon/sulfur composites cathode for lithium-sulfur batteries by nitrogen doping. Electrochim. Acta 2016, 202, 131-139. [CrossRef]

10. Jayaprakash, N.; Shen, J.; Moganty, S.; Corona, A.; Archer, L.A. Porous hollow carbon@sulfur composites for high-power lithium-sulfur batteries. Angew. Chem. Int. Ed. 2011, 50, 5904-5908. [CrossRef]

11. Wang, H.; Yang, Y.; Liang, Y.; Robinson, J.T.; Li, Y.; Jackson, A.; Cui, Y.; Dai, H. Graphene-wrapped sulfur particles as a rechargeable lithium-sulfur battery cathode material with high capacity and cycling stability. Nano Lett. 2011, 11, 2644-2647. [CrossRef]

12. Xiao, L.; Cao, Y.; Xiao, J. A soft approach to encapsulate sulfur: Polyaniline nanotubes for lithium-sulfur batteries with long cycle life. Adv. Mater. 2012, 24, 1176-1181. [CrossRef]

13. Zhao, M.; Zhang, Q.; Huang, J.; Tian, G.; Nie, J.; Peng, H.; Wei, F. Unstacked double-layer template graphene for high-rate lithium-sulphur batteries. Nat. Commun. 2014, 5, 3410. [CrossRef] [PubMed]

14. Cao, R.; Xu, W.; Lv, D.; Xiao, J.; Zhang, J. Anodes for rechargeable lithium-sulfur batteries. Adv. Energy Mater. 2015, 5, 513-537. [CrossRef]

15. Zhang, S.S. Role of $\mathrm{LiNO}_{3}$ in rechargeable lithium/sulfur battery. Electrochim. Acta 2012, 70, 344-348. [CrossRef]

16. Zheng, J.; Lv, D.; Gu, M.; Wang, C.M.; Zhang, J.; Liu, J.; Xiao, J. How to Obtain Reproducible results for lithium sulfur batteries. J. Electrochem. Soc. 2013, 160, A2288-A2292. [CrossRef]

17. Huang, J.; Zhang, Q.; Peng, H.; Liu, X.; Qian, W.; Wei, F. Ionic shield for polysulfides towards highly-stable lithium-sulfur batteries. Energy Environ. Sci. 2013, 7, 347-353. [CrossRef]

18. Shin, J.H.; Cairns, E.J. N-Methyl-(n-butyl) pyrrolidiniumbis (trifluoromethanesulfonyl) imide-LiTFSI-poly (ethylene glycol) dimethyl ether mixture as a Li/S cell electrolyte. J. Power Sources 2008, 177, 537-545. [CrossRef]

19. Suo, L.; Hu, Y.-S.; Li, H.; Armand, M.; Chen, L. A new class of solvent-in-salt electrolyte for high-energy rechargeable metallic lithium batteries. Nat. Commun. 2013, 4, 1481. [CrossRef]

20. Hu, J.; Long, G.; Liu, S.; Li, G.; Gao, X. A LiFSI-LiTFSI binary-salt electrolyte to achieve high capacity and cycle stability for a Li-S battery. Chem. Commun. 2014, 50, 14647-14650. [CrossRef]

21. Su, Y.S.; Manthiram, A. Lithium-sulphur batteries with a microporous carbon paper as a bifunctional interlayer. Nat. Commun. 2012, 3, 1166. [CrossRef]

22. $\mathrm{Fu}, \mathrm{Y}$;; Su, Y.S.; Manthiram, A. Highly reversible lithium/dissolved polysulfide batteries with carbon nanotube electrodes. Angew. Chem. 2013, 52, 6930-6935. [CrossRef] [PubMed]

23. Zhou, G.; Li, L.; Wang, D.; Shan, X.; Pei, S.; Li, F.; Cheng, H. A flexible sulfur-graphene-polypropylene separator integrated electrode for advanced Li-S batteries. Adv. Mater. 2015, 27, 641-647. [CrossRef] [PubMed]

24. Li, G.; Lei, W.; Luo, D.; Deng, Y.; Wang, D.; Chen, Z. 3D porous carbon sheets with multidirectional ion pathways for fast and durable lithium-sulfur batteries. Adv. Energy Mater. 2018, 8, 1702381. [CrossRef]

25. Shim, J.; Striebel, K.A.; Cairns, E.J. The Lithium/sulfur rechargeable cell effects of electrode composition and solvent on cell performance. J. Electrochem. Soc. 2001, 149, A1321-A1325. [CrossRef]

26. Wang, J.; Lu, L.; Ling, Z.; Yang, J.; Wan, C.; Jiang, C. Polymer lithium cells with sulfur composites as cathode materials. Electrochim. Acta 2003, 48, 1861-1867. [CrossRef]

27. Moreno, N.; Caballero, A.; Hernán, L.; Morales, J. Lithium-sulfur batteries with activated carbons derived from olive stones. Carbon 2014, 70, 241-248. [CrossRef]

28. Hernández-Rentero, C.; Córdoba, R.; Moreno, N.; Caballero, A.; Morales, J. Low-cost disordered carbons for Li/S batteries: A high-performance carbon with dual porosity derived from cherry pits. Nano Res. 2018, 11, 89-90. [CrossRef] 
29. Li, J.; Qin, F.; Zhang, L.; Zhang, K.; Li, Q.; Lai, Y.; Zhang, Z.; Fang, J. Mesoporous carbon from biomass: one-pot synthesis and application for Li-S batteries. J. Mater. Chem. A 2014, 2, 13916-13922. [CrossRef]

30. Chen, L.; Zhang, Y.; Lin, C.; Yang, W. Hierarchically porous nitrogen-rich carbon derived from wheat straw as an ultra-high-rate anode for lithium ion batteries. J. Mater. Chem. A 2014, 2, 9684-9690. [CrossRef]

31. Chung, S.H.; Manthiram, A. Carbonized eggshell membrane as a natural polysulfide reservoir for highly reversible li-s batteries. Adv. Mater. 2014, 26, 1360-1365. [CrossRef]

32. Gao, S.; Li, X.; Li, L.; Wei, X. A versatile biomass derived carbon material for oxygen reduction reaction, supercapacitors and oil/water separation. Nano Energy 2017, 33, 334-342. [CrossRef]

33. Dong, S.; He, X.; Zhang, H.; Xie, X.; Yu, M.; Yu, C.; Xiao, N.; Qiu, J. Surface modification of biomass-derived hard carbon by grafting porous carbon nanosheets for high-performance supercapacitors. J. Mater. Chem. A 2018, 6, 15954-15960. [CrossRef]

34. Sun, J.; Niu, J.; Liu, M.; Li, J.; Dou, M.; Wang, F. Biomass-derived nitrogen-doped porous carbons with tailored hierarchical porosity and high specific surface area for high energy and power density supercapacitors. Appl. Surf. Sci. 2018, 427, 807-813. [CrossRef]

35. Jin, H.; Li, J.; Yuan, Y.; Wang, J.; Lu, J.; Wang, S. Recent progress in biomass-derived electrode materials for high volumetric performance supercapacitors. Adv. Energy Mater. 2018, 8, 1801007. [CrossRef]

36. Lv, Y.; Gan, L.; Liu, M.; Xiong, W.; Xua, Z.; Zhu, D.; Wright, D.S. A self-template synthesis of hierarchical porous carbon foams based on banana peel for supercapacitor electrodes. J. Power Sources 2012, 209, $152-157$. [CrossRef]

37. Cheng, P.; Gao, S.; Zang, P.; Yang, X.; Bai, Y.; Xu, H.; Liu, Z.; Lei, Z. Hierarchically porous carbon by activation of shiitake mushroom for capacitive energy storage. Carbon 2015, 93, 315-324. [CrossRef]

38. Tian, W.; Gao, Q.; Tan, Y.; Yang, K.; Zhu, L.; Yang, C.; Zhang, H. Bio-inspired beehive-like hierarchical nanoporous carbon derived from bamboo-based industrial byproduct as high performance supercapacitor electrode material. J. Mater. Chem. A 2015, 3, 5656-5664. [CrossRef]

39. Cheng, P.; Li, T.; Yu, H.; Zhi, L.; Liu, Z.; Lei, Z. Biomass-derived carbon fiber aerogel as a binder-free electrode for high-rate supercapacitors. J. Phys. Chem. C 2016, 120, 2079-2086. [CrossRef]

40. Li, Y.; Wang, G.; Wei, T.; Fan, Z.; Yan, P. Nitrogen and sulfur co-doped porous carbon nanosheets derived from willow catkin for supercapacitors. Nano Energy 2016, 19, 165-175. [CrossRef]

41. Hao, Y.; Xu, F.; Qian, M.; Xu, J.; Zhao, W.; Huang, F. Low-cost and massive preparation of nitrogendoped porous carbon for supercapacitor application. RSC Adv. 2017, 7, 10901-10905. [CrossRef]

42. Chen, X.; Zhang, J.; Zhang, B.; Dong, S.; Guo, X.; Mu, X.; Fei, B. A novel hierarchical porous nitrogen-doped carbon derived from bamboo shoot for high performance supercapacitor. Sci. Rep. 2017, 7, 7362. [CrossRef] [PubMed]

43. An, Y.; Li, Z.; Yang, Y.; Guo, B.; Zhang, Z.; Wu, H.; Hu, Z. Synthesis of hierarchically porous nitrogen-doped carbon nanosheets from agaric for high-performance symmetric supercapacitors. Adv. Mater. Interfaces 2017, 4, 1700033. [CrossRef]

44. Minzae, L.; Gil-Pyo, K.; Hyeon Don, S.; Soomin, P.; Jongheop, Y. Preparation of energy storage material derived from a used cigarette filter for a supercapacitor electrode. Nanotechnology 2014, 25, 345601.

45. Wang, H.; Xu, Z.; Kohandehghan, A.; Li, Z.; Cui, K.; Tan, X.; Stephenson, T.J.; King'ondu, C.K.; Holt, C.M.B.; Olsen, B.C.; et al. Interconnected carbon nanosheets derived from hemp for ultrafast supercapacitors with high energy. ACS Nano 2013, 7, 5131-5141. [CrossRef] [PubMed]

46. Li, Z.; Zhang, L.; Amirkhiz, B.S.; Tan, X.; Xu, Z.; Wang, H.; Olsen, B.C.; Holt, C.M.B.; Mitlin, D. Carbonized chicken eggshell membranes with $3 \mathrm{~d}$ architectures as high-performance electrode materials for supercapacitors. Adv. Energy Mater. 2012, 2, 431-437. [CrossRef]

(C) 2019 by the authors. Licensee MDPI, Basel, Switzerland. This article is an open access article distributed under the terms and conditions of the Creative Commons Attribution (CC BY) license (http:/ / creativecommons.org/licenses/by/4.0/). 